\title{
Myocardial Protein Turnover in Patients with Coronary Artery Disease Effect of Branched Chain Amino Acid Infusion
}

Lawrence H. Young, Patrick H. McNulty, Cheryl Morgan, Lawrence I. Deckelbaum, Barry L. Zaret, and Eugene J. Barrett Sections of Cardiology and Endocrinology, Department of Internal Medicine, Yale University School of Medicine, New Haven, Connecticut 06510

\begin{abstract}
The regulation of protein metabolism in the human heart has not previously been studied. In 10 postabsorptive patients with coronary artery disease, heart protein synthesis and degradation were estimated simultaneously from the extraction of intravenously infused $\mathrm{L}-\left[\right.$ ring $\left.-2,6-{ }^{3} \mathrm{H}\right]$ phenylalanine (PHE) and the dilution of its specific activity across the heart at isotopic steady state. We subsequently examined the effect of branched chain amino acid (BCAA) infusion on heart protein turnover and on the myocardial balance of amino acids and branched chain ketoacids (BCKA) in these patients.

In the postabsorptive state, there was a net release of phenylalanine (arterial-cardiac venous $[\mathrm{PHE}]=-1.71 \pm 0.32 \mathrm{nmol} /$ $\mathrm{ml}, P<0.001 ;$ balance $=-116 \pm 21 \mathrm{nmol} \mathrm{PHE} / \mathrm{min}, P$ $<0.001)$, reflecting protein degradation (142 \pm 40 nmol PHE/ $\mathrm{min})$ in excess of synthesis $(24 \pm 42 \mathrm{nmol}$ PHE/min) and net myocardial protein catabolism. During BCAA infusion, protein synthesis increased to equal the degradation rate $(106 \pm 24$ and $106 \pm 28 \mathrm{nmol} \mathrm{PHE} / \mathrm{min}$, respectively) and the phenylalanine balance shifted $(P=0.01)$ from negative to neutral (arterialcardiac venous $[\mathrm{PHE}]=0.07 \pm 0.36 \mathrm{nmol} / \mathrm{ml}$; balance $=2 \pm 25$ nmol PHE/min). BCAA infusion stimulated the myocardial uptake of both BCAA $(P<0.005)$ and their ketoacid conjugates $(P<0.001)$ in proportion to their circulating concentrations. Net uptake of the BCAA greatly exceeded that of other essential amino acids suggesting a role for BCAA and BCKA as metabolic fuels. Plasma insulin levels, cardiac double product, coronary blood flow, and myocardial oxygen consumption were unchanged. These results demonstrate that the myocardium of postabsorptive humans is in negative protein balance and indicate a primary anabolic effect of BCAA on the human heart. ( $J$. Clin. Invest. 1991. 87:554-560.) Key words: cardiac metabolism • phenylalanine • protein degradation • protein synthesis
\end{abstract}

\section{Introduction}

Although several investigators have reported measurements of the balance of amino acids across the heart in humans (1-4), direct measurements of protein synthesis and degradation have

This work was presented in part at the November 1989 national meeting of the American Heart Association, New Orleans, LA.

Address reprint requests to Dr. Young, Section of Cardiology, Yale University School of Medicine, 333 Cedar Street, New Haven, CT 06510 . 1990.

Received for publication 16 April 1990 and in revised form $30 \mathrm{July}$

J. Clin. Invest.

(c) The American Society for Clinical Investigation, Inc.

$0021-9738 / 91 / 02 / 0554 / 07 \$ 2.00$

Volume 87, February 1991, 554-560 been precluded by the difficulty in sampling heart protein directly in humans. As a result the responsiveness of protein synthesis and degradation in the human heart to humoral or hemodynamic factors remains unknown. Recently developed techniques utilizing measurements of labeled phenylalanine kinetics have provided simultaneous estimates of muscle protein synthesis, degradation, and overall protein balance in both skeletal muscle $(5,6)$ and the heart $(7,8)$ in vivo. This approach permits measurement of short-term changes in each of these parameters in the same subject. In addition, since tissue sampling is not required the technique is applicable to clinical investigation. In the current study we report the first measurements of cardiac protein synthesis and degradation in patients with coronary artery disease. These measurements were obtained both in the postabsorptive state and during the last 15 min of a 75-min infusion of branched-chain amino acids (BCAA). ${ }^{1}$

The BCAA, which include the three essential amino acids leucine, isoleucine, and valine, were selected for study since they appear to have anabolic effects on protein metabolism in muscle tissue (9-17). In vitro, the BCAA stimulate protein synthesis and inhibit protein degradation in heart (9-11) and skeletal muscle $(12,13)$. In human beings, increasing the circulating concentration of BCAA promotes protein anabolism by the whole body (14) and by forearm skeletal muscle (15). Somewhat variable effects of BCAA given in vivo on protein synthesis are reported in rat skeletal $(16-18)$ and heart $(17,18)$ muscle. In addition to a potential role in regulating protein turnover, BCAA can be used as an oxidative fuel by heart (19) which has high levels of BCAA transaminase and branchedchain ketoacid (BCKA) dehydrogenase (20). The relationship, if any, between their oxidation and their modulation of protein metabolism is not known. In the current study, the myocardial utilization of these amino acids and their ketoacid analogues was measured and compared to that of other essential and nonessential amino acids to assess whether there was significant oxidation of these substrates by the human heart.

\section{Methods}

Study population. Nine men and one woman, aged 52-76 yr, were selected from patients scheduled to undergo diagnostic cardiac catheterization for the evaluation of coronary artery disease. Patients with evidence of prior anterior wall $\mathrm{Q}$ wave myocardial infarction, congestive heart failure, left bundle branch block, a history of a bleeding diathesis, or active ischemia at rest were excluded from study. Medications including $\beta$ blockers (six patients) calcium channel antagonists (eight patients), and nitrates (seven patients) were continued. Informed writ-

1. Abbreviations used in this paper: BCAA, branched-chain amino acid(s); BCKA, branched-chain ketoacid(s); GCV, great cardiac vein; KIC, $\alpha$-ketoisocaproate; KIV, $\alpha$-ketoisovalerate; KMV, $\alpha$-ketomethylvalerate. 
ten consent was obtained from each patient before participation in this study. Subsequent coronary angiography revealed stenoses in the left anterior descending artery (seven patients), the left circumflex artery (nine patients), and the right coronary artery (eight patients).

Experimental protocol. All patients were studied after an overnight $(12-18 \mathrm{~h}$ ) fast and before diagnostic angiography. A number $7 \mathrm{~F}$ thermodilution coronary sinus flow catheter (Elecath Corp., Rahway, NJ) was introduced via the right internal jugular vein and the tip was advanced into the great cardiac vein (GCV) to selectively sample venous drainage from the anterior wall of the left ventricle, a territory supplied by the left anterior descending coronary artery. GCV sampling avoids the problems of catheter instability and mixing with blood from the right atrium associated with more proximal placement. Fluoroscopic examination and measurements of oxygen saturation confirmed catheter placement. An introducer sheath (U.S.C.I. Div., C. R. Bard, Inc., Billerica, MA) in the right femoral artery was used for sampling blood and subsequent left heart catheterization. Catheters were maintained patent by the slow infusion of heparinized saline (total dose $\leq 75 \mathrm{U}$ over $90 \mathrm{~min}$ ).

L-[ring-2,6- ${ }^{3} \mathrm{H}$ ]phenylalanine $(50 \mu \mathrm{Ci} / \mathrm{h})$ was infused continuously into the left antecubital vein beginning $60 \mathrm{~min}$ before obtaining basal samples and continuing throughout the study. Basal samples for determination of arterial and GCV plasma amino acid and ketoacid concentration, phenylalanine specific activity, glucose and lactate concentration, and arterial insulin were drawn in quadruplicate over a $15-\mathrm{min}$ period. Thermodilution coronary sinus flow was measured in duplicate. Heart rate and arterial blood pressure were measured throughout. After obtaining basal samples, a primed $(47 \mu \mathrm{mol} / \mathrm{kg}$ per min for 10 $\mathrm{min}$ ) continuous $(5.2 \mu \mathrm{mol} / \mathrm{kg}$ per min for $65 \mathrm{~min}$ ) infusion of BCAA (BranchAmin, Clintec International, Deerfield, IL) was administered. Patients received a total volume of $2.6 \mathrm{ml} / \mathrm{kg}$ of this $4 \%$ equimolar solution containing $105 \mu \mathrm{mol} / \mathrm{ml}$ each of valine, leucine, and isoleucine. During the last $15 \mathrm{~min}$ of the 75-min BCAA infusion, arterial and GCV samples were obtained every $5 \mathrm{~min}$, and thermodilution coronary blood flow and hemodynamic measurements were performed.

In view of the heterogeneity of the patient population and the ethical concern that each patient only be studied once, the protocol was designed to allow each patient to serve as his or her own control with comparisons of substrate balance and phenylalanine kinetics made before and during BCAA infusion.

Analytic methods. Blood glucose and lactate concentrations were measured using the glucose and lactate oxidase methods (Yellow Springs Instrument Co., Yellow Springs, $\mathrm{OH}$ ). Plasma insulin was determined by double-antibody radioimmunoassay. Arterial plasma free fatty acids were measured using a microfluorometric technique with oleic acid as a standard. Concentrations of acidic and neutral amino acids were measured in sulfosalicylic acid extracts of plasma with an automated ion-exchange chromatographic technique (model D-500, Dionex Corp., Sunnyvale, CA).

For the determination of phenylalanine specific activity, $2 \mathrm{ml}$ of acidified plasma was placed on a Dowex 50G cation-exchange resin column (Bio-Rad Laboratories, Richmond, CA). The column was washed with $0.01 \mathrm{~N} \mathrm{HCl}$, and the acid eluate was collected and frozen for subsequent measurement of the BCKA $\alpha$-ketoisocaproate (KIC), $\alpha$-ketomethylvalerate (KMV), and $\alpha$-ketoisovalerate (KIV) (21). Amino acids retained on the Dowex column were eluted with $4 \mathrm{M}$ $\mathrm{NH}_{4} \mathrm{OH}$. The eluate was dried and the residue was dissolved in $800 \mu \mathrm{l}$ of $2 \%$ (wt/vol) trichloroacetic acid. After centrifugation, a 200- $\mu$ l aliquot was analyzed using an ion-pair, reverse-phase HPLC technique. The mobile phase consisted of $16 \%$ methanol (vol/vol) containing a phosphoric acid buffer (pH 5) and heptane sulfonic acid added as an ion pairing agent (low UV-PIC B7 reagent, Waters Associates, Milford, MA). The column flow rate was $1.2 \mathrm{ml} / \mathrm{min}$. The column eluate was monitored for UV absorbance at wavelength $214 \mathrm{~nm}$. With $200-\mu 1$ samples injected onto a $4.6 \times 250$-mm Ultrasphere ODS $(C-18,5 \mu \mathrm{m})$ column (Beckman Instruments, Inc., Palo Alto, CA), a sharply separated phenylalanine peak eluted at 14-16 min. This fraction was collected in scintillation vials and subsequently counted for ${ }^{3} \mathrm{H}$ radioactiv- ity. Specific activity was calculated as the ${ }^{3} \mathrm{H}$ radioactivity divided by phenylalanine mass. The coefficients of variation of phenylalanine concentration and specific activity, measured in this manner, averaged $1.8 \%$ and $2.2 \%$, respectively. By comparison, the measurement of phenylalanine concentration using ion-exchange chromatography as part of an amino acid profile has a coefficient of variation of 5-7\%.

Calculations. The net myocardial balances of glucose, lactate, and amino acids were calculated from the product of the arterial-coronary sinus concentration difference and coronary flow.

Net balance $=([A]-[G C V]) \times$ flow,

where $[A]$ and $[G C V]$ are the arterial and GCV concentrations and flow is the thermodilution coronary flow. Myocardial oxygen consumption was calculated from the difference in blood oxygen content calculated from the hemoglobin concentration and $\mathrm{O}_{2}$ saturation.

Rates of myocardial protein synthesis and degradation were calculated from the extraction of labeled phenylalanine and the dilution of phenylalanine specific activity across the heart, respectively $(7,8)$. Because phenylalanine is neither synthesized nor metabolized in muscle, at steady state the measured rate of disappearance of tracer across the heart reflects the rate of incorporation of phenylalanine into protein $(7$, 8 ). In addition, the dilution of phenylalanine specific activity across the heart at steady state reflects the release of unlabeled phenylalanine from muscle protein into plasma $(7,8)$. The rate of phenylalanine release from muscle protein is calculated according to the equation:

Phenylalanine release $=\left\{\left(S A_{\mathrm{A}} / S A_{\mathrm{GCV}}\right)-1\right\} \times[A] \times$ flow,

where $S A_{\mathrm{A}}$ and $S A_{\mathrm{GCV}}$ denote the specific activity (dpm/nmol) of phenylalanine in the artery and GCV, respectively. The uptake of phenylalanine into newly synthesized protein is calculated from the extraction of labeled phenylalanine from plasma using GCV specific activity to approximate the precursor specific activity at which phenylalanine is incorporated into protein. The immediate precursor pool for protein synthesis is the phenylalanyl-tRNA which equilibrates rapidly with the plasma in the rat heart $(7,22)$. The rate of phenylalanine incorporation into protein is expressed in the following equation:

Phenylalanine uptake $=\left(D P M_{\mathrm{A}}-D P M_{\mathrm{GCV}}\right) / S A_{\mathrm{GCV}} \times$ flow.

Eqs. 2 and 3 each make the assumption that phenylalanine released from muscle protein degradation is reutilized for new protein synthesis in a similar fashion to phenylalanine entering muscle from arterial plasma.

Statistical analysis. All data are presented as mean values \pm SEM. Data presented as "basal" and "BCAA infusion" represent the mean values of quadruplicate samples drawn during those periods (from -15 to 0 and from 60 to $75 \mathrm{~min}$, respectively) and are compared using a paired Student's $t$ test.

\section{Results}

Myocardial glucose, lactate, and oxygen balance and hemodynamics. In the postabsorptive period, the plasma glucose concentration averaged $5.3 \pm 0.2 \mathrm{mM}$ and blood lactate $0.8 \pm 0.1$ $\mathrm{mM}$. There was a net uptake of both substrates by the myocardium which averaged $4.2 \pm 2.6$ and $10.0 \pm 2.6 \mu \mathrm{mol} / \mathrm{min}$ for glucose and lactate respectively. Although all 10 subjects had demonstrable coronary artery disease, myocardial lactate extraction averaged $23 \pm 5 \%(P<0.001)$ with only one subject having a minimal net lactate release $(0.01 \mu \mathrm{mol} / \mathrm{ml})$ during the basal period. With BCAA infusion the arterial glucose and lactate concentrations remained stable; there was no change in the myocardial glucose balance, but a small decrease in heart lactate uptake (Table I). Plasma insulin in the basal period averaged $16 \pm 2 \mu \mathrm{U} / \mathrm{ml}$ and was unchanged by BCAA administration. Arterial free fatty acid levels remained constant, averag- 
Table I. Glucose and Lactate Concentrations and Myocardial Balance

\begin{tabular}{|c|c|c|c|c|}
\hline & \multicolumn{2}{|c|}{ Arterial concentration } & \multicolumn{2}{|c|}{ Myocardial balance } \\
\hline & Glucose & Lactate & Glucose & Lactate \\
\hline & \multicolumn{2}{|c|}{$m M$} & \multicolumn{2}{|c|}{$\mu \mathrm{mol} / \mathrm{min}$} \\
\hline Basal & $5.3 \pm 0.2$ & $0.8 \pm 0.1$ & $4.2 \pm 2.6$ & $10.0 \pm 2.6^{*}$ \\
\hline BCAA infused & $5.4 \pm 0.3$ & $0.7 \pm 0.1$ & $6.0 \pm 2.1^{\ddagger}$ & $7.0 \pm 2.0^{\text {s1 }}$ \\
\hline
\end{tabular}

Symbols denote significance of balance different from $0:{ }^{*} P<0.005$; ${ }^{\ddagger} P<0.02 ;{ }^{\S} P<0.01$; or difference from basal ${ }^{1} P<0.05$.

ing $1,600 \pm 72 \mu \mathrm{M}$ basally and $1,597 \pm 76 \mu \mathrm{M}$ during the BCAA infusion.

The coronary blood flow averaged $73 \pm 2 \mathrm{ml} / \mathrm{min}$ in the basal period and was unchanged by amino acid infusion (Table II). Similarly, we observed no change in the myocardial oxygen consumption, mean arterial blood pressure, heart rate, or cardiac double product during the course of the study (Table II). The low basal heart rate likely reflects the continued use of $\beta$-blocking agents in six patients.

Plasma amino acid concentrations and myocardial amino acid balances. The arterial concentrations, arterial-GCV concentration differences and myocardial balances for nine amino acids during the basal period and over the last $15 \mathrm{~min}$ of the 75-min BCAA infusion are shown in Table III. In the basal state there was a net myocardial uptake of glutamate, leucine, isoleucine, and total BCAA and a net release of alanine, glutamine, and phenylalanine. Infusion of BCAA led to a marked rise in the arterial BCAA concentration and to a significant increase in the myocardial uptake of these amino acids (Table III). The arterial concentrations of alanine, glutamate, tyrosine, and phenylalanine fell significantly in response to the BCAA whereas plasma glutamine concentrations remained stable. The net myocardial balance for both alanine and glutamine remained negative during the BCAA infusion and were similar to basal. The net balance for phenylalanine across the myocardium changed from a significant net release to essentially zero in response to the BCAA infusion. Although this change was apparent using results from either the ion-exchange chromatographic or the HPLC analysis (Table III), it was statistically significant only with the use of the latter technique $(P=0.01)$.

Branched chain ketoacid concentrations and myocardial balances. The arterial concentrations, arterial-GCV concen-

Table II. Myocardial Blood Flow, Myocardial Oxygen Consumption, Heart Rate, and Blood Pressure

\begin{tabular}{lccccc}
\hline & $\mathrm{CBF}$ & $\mathrm{MVO}_{2}$ & $\begin{array}{c}\text { Mean } \\
\text { blood } \\
\text { pressure }\end{array}$ & $\begin{array}{c}\text { Heart } \\
\text { rate }\end{array}$ & $\begin{array}{c}\text { Double } \\
\text { product }\end{array}$ \\
\hline & $\mathrm{ml} / \mathrm{min}$ & $\mathrm{ml} / \mathrm{min}$ & $\mathrm{mm} \mathrm{Hg}$ & $\mathrm{min}^{-1}$ & $\begin{array}{c}\mathrm{mm} \mathrm{Hg} \times \mathrm{min} \\
\times 10^{-3}\end{array}$ \\
Basal & $73 \pm 2$ & $8.3 \pm 0.5$ & $107 \pm 7$ & $59 \pm 3$ & $9.2 \pm 1.1$ \\
BCAA infused & $75 \pm 4$ & $8.1 \pm 0.7$ & $106 \pm 7$ & $57 \pm 4$ & $9.1 \pm 1.0$ \\
\hline
\end{tabular}

$\mathrm{CBF}$, coronary blood flow measured in the great cardiac vein; $\mathrm{MVO}_{2}$, myocardial oxygen consumption; double product, systolic blood pressure multiplied by heart rate. tration differences, and myocardial extraction ratios and net balances for KIC, KIV, and KMV and for the BCAA are given in Table IV. In the basal period there was a significant net uptake of each of the BCKA. Although the arterial BCKA concentrations averaged only $12-25 \%$ of their amino acid conjugates, they were extracted with greater avidity by the heart (Table IV); as a result they supplied a similar amount of amino acid carbon skeleton to the myocardium $(0.56$ and $0.76 \mu \mathrm{mol} /$ min, for BCKA and BCAA respectively).

During the BCAA infusion, the arterial BCKA concentrations increased approximately twofold. The net myocardial uptake of BCKA nearly tripled (Table IV); this increase was less than that observed for the BCAA uptake, owing to a less marked rise in the BCKA concentration. In these studies we observed a strong correlation between the arterial concentration and heart uptake for total BCKA $(r=0.85, P<0.001)$ (Fig. 1) which was also apparent for each of the individual BCKA (KIC $r=0.85$, KIV $r=0.97$, and KMV $r=0.83$; all $P$ $<0.001)$. In contrast, this relationship was less dramatic for the total BCAA $(r=0.69, P<0.005)$; despite a strong correlation for leucine $(r=0.82, P<0.001)$, there was a less striking correlation for isoleucine $(r=0.65, P<0.01)$ and valine $(r=0.45, P$ $=\mathrm{NS}$ ).

Phenylalanine kinetics. In every patient during the basal period we observed a higher phenylalanine concentration in the GCV than in arterial plasma (mean difference $1.71 \pm 0.32$ $\mathrm{nmol} / \mathrm{ml}, P<0.001$, range $0.13-3.13 \mathrm{nmol} / \mathrm{ml}$ ). The net release of phenylalanine during the basal period averaged $116 \pm 21 \mathrm{nmol} / \mathrm{min}$, indicating that protein degradation by the myocardium exceeded protein synthesis in these postabsorptive patients. During BCAA infusion arterial and GCV phenylalanine concentrations were equal (mean arterial-GCV difference $=0.07 \pm 0.36 \mathrm{nmol} / \mathrm{ml}, P=\mathrm{NS}$ ). The myocardial balance for phenylalanine fell $(P=0.01)$ essentially to zero, indicating that protein synthesis and proteolysis were occuring at equal rates (Fig. 2).

Using the dilution of phenylalanine specific activity between arterial and GCV plasma as a measure of proteolysis, we observed a significant release of unlabeled phenylalanine during the basal period $(142 \pm 40 \mathrm{nmol} / \mathrm{min}, P<0.005)$ and during BCAA infusion $(106 \pm 24 \mathrm{nmol} / \mathrm{min}, P<0.001)$. In the basal state, the rate of myocardial protein synthesis $(24 \pm 42 \mathrm{nmol} /$ $\mathrm{min}$ ) estimated from the extraction of radiolabeled phenylalanine was not significantly different from zero. However, during BCAA infusion there was a significant tracer extraction by the myocardium $(3 \pm 1 \%, P<0.005)$ and the estimated rate of myocardial protein synthesis increased to $106 \pm 28 \mathrm{nmol} / \mathrm{min}$.

The combination of the increased rate of myocardial protein synthesis and the modest decline in proteolysis accounted for the significant net anabolic change in the phenylalanine balance that accompanied BCAA infusion. Interestingly, when the change in net phenylalanine balance was examined in individual patients as a function of the initial myocardial phenylalanine balance, we observed a highly significant correlation, i.e., those patients displaying the most negative phenylalanine balances in the postabsorptive state had the most marked anabolic response to BCAA infusion (Fig. 3).

\section{Discussion}

This study provides what we believe to be the first measurements of myocardial protein turnover in humans. In postab- 
Table III. Arterial Amino Acid Concentrations, Myocardial Amino Acid Extraction, and Balance

\begin{tabular}{|c|c|c|c|c|c|c|c|c|c|}
\hline & \multicolumn{3}{|c|}{ Arterial concentration } & \multicolumn{3}{|c|}{ Arterial-GCV difference } & \multicolumn{3}{|c|}{ Myocardial balance } \\
\hline & Basal & BCAA infused & $P$ & Basal & BCAA infused & $P$ & Basal & BCAA infused & $P$ \\
\hline & \multicolumn{3}{|c|}{$\mathrm{nmol} / \mathrm{ml}$} & \multicolumn{3}{|c|}{$\mathrm{nmol} / \mathrm{ml}$} & \multicolumn{3}{|c|}{$\mu \mathrm{mol} / \mathrm{min}$} \\
\hline Leu & $151 \pm 12$ & $602 \pm 21$ & 0.001 & $11.2 \pm 2.9^{\ddagger}$ & $46.1 \pm 6.7^{\ddagger}$ & 0.001 & $0.41 \pm 0.09^{*}$ & $1.87 \pm 0.30^{\ddagger}$ & 0.001 \\
\hline Ile & $73 \pm 6$ & $502 \pm 22$ & 0.001 & $4.1 \pm 1.6^{8}$ & $25.3 \pm 5.4^{*}$ & 0.005 & $0.15 \pm 0.05^{5}$ & $1.02 \pm 0.24^{*}$ & 0.01 \\
\hline Val & $250 \pm 20$ & $827 \pm 26$ & 0.001 & $6.0 \pm 4.1$ & $21.9 \pm 10.0$ & NS & $0.20 \pm 0.13$ & $0.89 \pm 0.43$ & NS \\
\hline BCAA & $474 \pm 37$ & $1931 \pm 64$ & 0.001 & $21.4 \pm 8.4^{\S}$ & $93.3 \pm 20.1^{*}$ & 0.01 & $0.75 \pm 0.26^{\prime}$ & $3.77 \pm 0.88^{*}$ & 0.01 \\
\hline Glu & $92 \pm 12$ & $82 \pm 11$ & 0.001 & $53.5 \pm 5.7^{\ddagger}$ & $46.6 \pm 6.1^{\ddagger}$ & 0.02 & $1.97 \pm 0.16^{\ddagger}$ & $1.82 \pm 0.20^{\ddagger}$ & NS \\
\hline Gln & $507 \pm 20$ & $520 \pm 21$ & NS & $-32.9 \pm 7.8^{*}$ & $-31.2 \pm 12.7^{\S}$ & NS & $-1.27 \pm 0.35^{1}$ & $-1.21 \pm 0.53$ & NS \\
\hline Ala & $325 \pm 42$ & $287 \pm 32$ & 0.05 & $-28.1 \pm 4.6^{\ddagger}$ & $-25.8 \pm 7.4^{\prime}$ & NS & $-1.03 \pm 0.15^{\ddagger}$ & $-0.97 \pm 0.27^{1}$ & NS \\
\hline Tyr & $61 \pm 4$ & $54 \pm 4$ & 0.001 & $-1.6 \pm 1.3$ & $-1.4 \pm 0.4^{*}$ & NS & $-0.07 \pm 0.06$ & $-0.06 \pm 0.02^{\prime}$ & NS \\
\hline Phe & $61 \pm 3$ & $52 \pm 3$ & 0.001 & $-0.9 \pm 0.9$ & $1.1 \pm 0.6$ & NS & $-0.04 \pm 0.04$ & $0.05 \pm 0.03$ & NS \\
\hline$P h e^{* *}$ & $58 \pm 2$ & $49 \pm 3$ & 0.001 & $-1.71 \pm 0.32^{\ddagger}$ & $0.07 \pm 0.36$ & 0.01 & $-0.12 \pm 0.02^{\ddagger}$ & $0.00 \pm 0.02$ & 0.01 \\
\hline
\end{tabular}

$P$ values in table refer to differences between basal and BCAA infused values. Symbols denote the significance of myocardial extraction (arterial-GCV concentration difference) or balance different from $0:^{*} P<0.005 ;^{\ddagger} P<0.001 ;^{5} P<0.05 ;^{1} P<0.02 ;^{\prime} P<0.01$. Amino acid values were measured by ion exchange except Phe**, which was measured by HPLC.

sorptive patients with coronary artery disease, the heart was in negative protein balance and short-term infusion of BCAA had an anabolic effect on heart protein metabolism. In addition, both the BCAA and their ketoacid derivatives were taken up by the human heart and this uptake was enhanced by increasing their circulating concentrations.

The experimental approach used has previously been applied by our laboratory and others to measure the synthesis and degradation of skeletal muscle protein both in the basal state ( 5 , $6,23)$ and after the acute administration of insulin (5) or amino acids (15). Both radiotracer $(5,6)$ and stable isotope $(23)$ methods have been used to measure the specific activity (enrichment) of phenylalanine in arterial blood and in venous blood draining a muscle bed. Extension of this method to the study of the heart, while theoretically straightforward, posed some practical difficulties. First among these was the precision of the measurement of phenylalanine balance and specific activity. Heart muscle, because of its continuous work load and high metabolic demands, has a blood flow of $80-100 \mathrm{ml} / 100 \mathrm{~g}$ per min or $\sim 20$-fold greater than that of resting human skeletal muscle (3-6 ml/100 g per min). Consequently, unless the utilization of a particular substrate increases in proportion to the increased blood flow, the arterial-venous difference for that substrate is smaller and therefore more difficult to quantitate precisely. This is easily seen by comparing the dilution of phenylalanine specific activity across the heart observed in the current study $(7 \pm 1 \%)$ with that observed previously in human forearm ( $35 \%$, reference 5$)$ or canine hindlimb $(38 \%$, reference 6) skeletal muscle. In the earlier studies, phenylalanine specific activity was determined from routine ion-exchange measurements of plasma amino acids using an amino acid analyzer and the radioactivity eluted by an $\mathrm{NH}_{4} \mathrm{OH}$ wash of a Dowex cation exchange column (see Methods). In the current studies, we have developed an HPLC method with improved precision for measurement of both the phenylalanine concentration and specific activity which greatly facilitates the use of the isotope dilution method in the heart. Presumably, stable isotopic methods with gas chromatography-mass spectroscopy analysis, which

Table IV. BCKA and BCAA Concentrations, Myocardial Extraction Ratio, Extraction, and Balance

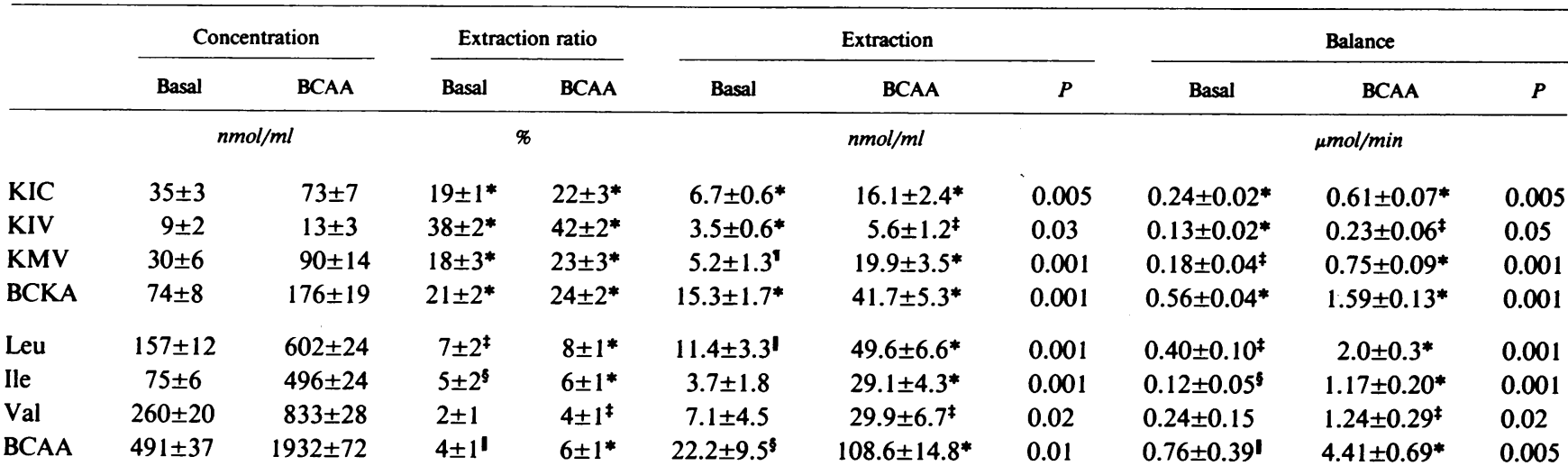

$P$ values in table refer to differences between basal and BCAA infused values. Symbols denote significance of myocardial extraction or balance different from $0:^{*} P<0.001{ }^{*} P<0.005 ;^{8} P<0.05$ ' $^{1} P<0.02 ;^{1} P<0.01 . n=8$ patients who had both BCAA and BCKA measurements. 


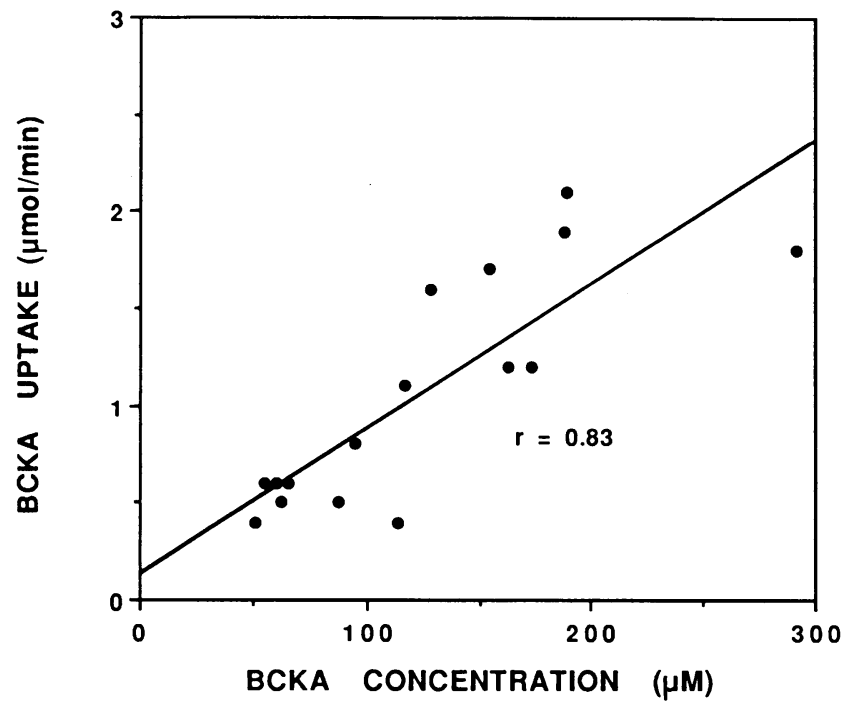

Figure 1. Correlation between the concentration of total BCKA and the myocardial uptake of these ketoacids. Points represent mean values of quadruplicate samples for individual patients in the postabsorptive state and during the last $15 \mathrm{~min}$ of BCAA infusion.

typically allow measurements of isotopic enrichment with a precision of $<1 \%$, could also be used. These methods have recently been applied to studies of skeletal muscle turnover in humans (23). With either radioisotopes or stable isotopes, the
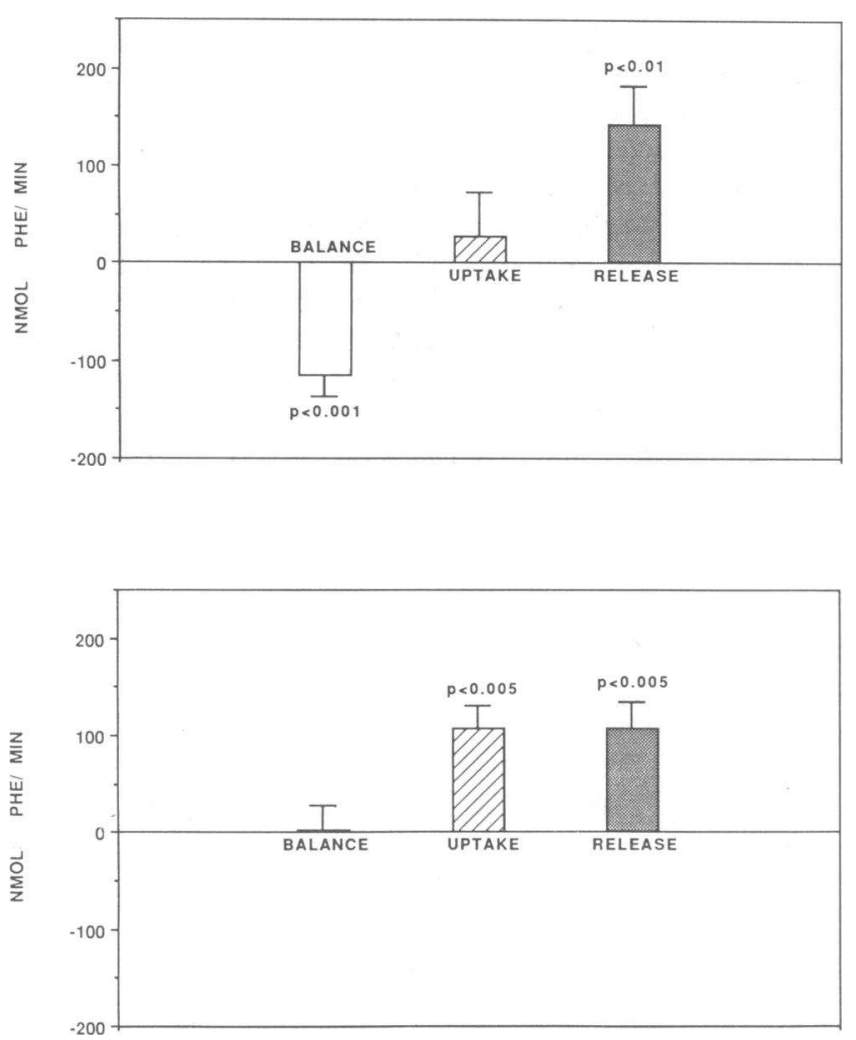

Figure 2. Myocardial phenylalanine balance (from Eq. 1), uptake (from Eq. 3) and release (from Eq. 2) in the postabsorptive state (upper panel) and during the last $15 \mathrm{~min}$ of BCAA infusion (lower panel). The change in myocardial phenylalanine balance was significant with $P=0.01$.

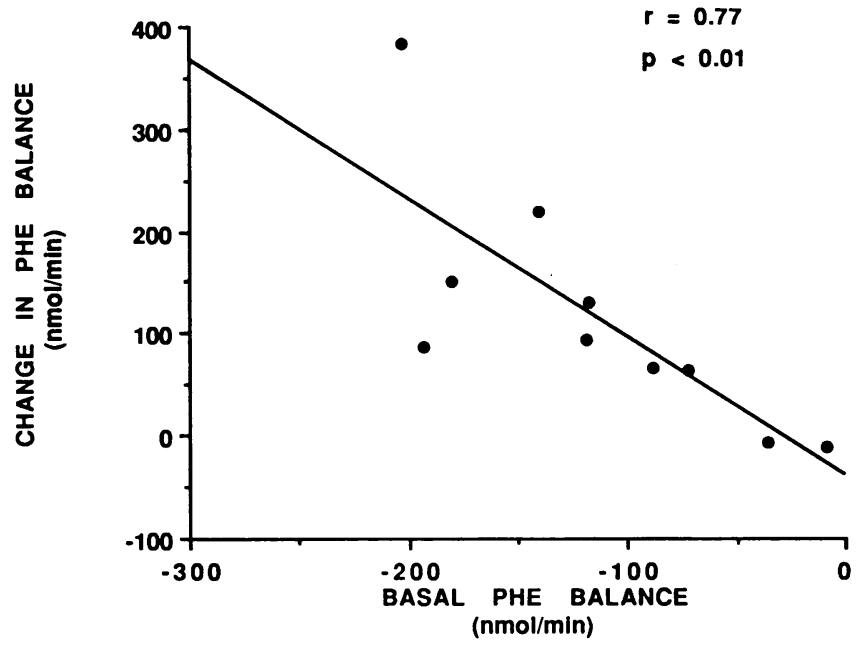

Figure 3. Relationship between basal heart phenylalanine balance and the change in phenylalanine balance during BCAA infusion in individual patients.

fractional isotopic extraction or dilution across the muscle will be smaller and somewhat more difficult to measure when plasma phenylalanine concentrations are elevated as might occur during infusion of a complete amino acid mixture. This issue was factored into our decision to study the effects of infused BCAA, rather than a complete amino acid mixture which might also have an anabolic effect on the heart (17).

Combining improved analytic methods with quadruplicate samples of arterial and GCV blood during basal and experimental periods provides new information on both the turnover of protein by the heart as well as the metabolism of other amino acids. In previous studies of amino acid balance across the human myocardium, a net release of alanine has consistently been noted but the balances of glutamate, the BCAA, glutamine and phenylalanine have varied widely $(1-4)$. Using multiple samples of arterial and coronary sinus plasma obtained both during a basal period and during amino acid infusion we previously observed in a conscious canine model a significant uptake of BCAA, and a release of alanine, glutamine, and glycine (24). The uptake of BCAA increased during infusion of a balanced mixture of amino acids without significant changes in the myocardial balance of other amino acids (24). The results in those canine studies are quite similar to those seen here in humans with two exceptions: there was no significant net uptake of glutamate by the dog heart and no net release of phenylalanine. The former finding appears to relate to a true species difference since glutamate was the most avidly extracted amino acid in the human heart and the analytic methods for measurement of glutamate were identical in the two studies. The lack of net phenylalanine release by postabsorptive canine heart (24) appears more likely owing to the different analytic procedure used. In support of this, in more recent canine studies we have also observed significant net phenylalanine release by the heart postabsorptively using the more precise $\operatorname{HPLC}$ method $(7,25)$.

Throughout the present study, we observed not only net cardiac uptake of the BCAA, but also of BCKA (Table III). As $B C K A$ levels increased during $B C A A$ infusion (because of their synthesis from BCAA in other tissues), the heart continued to extract these substances with high efficiency. Although the fate of the BCAA and BCKA extracted by the heart cannot be ascer- 
tained from these experiments, several considerations would point to the likelihood that a significant fraction are oxidized. First, both the BCAA transaminase and the BCKA dehydrogenase enzymes, responsible for the initial steps towards oxidation of these substances, are abundantly present in heart (20). This contrasts with skeletal muscle which contains less BCKA dehydrogenase (20) and does not extract appreciable amounts of BCKA from the circulation (15). Secondly, it seems unlikely that a major part of the net BCAA uptake can be accounted for by incorporation into protein in that net uptake of other essential amino acids (phenylalanine, tyrosine, and threonine) would be expected and was not observed. If indeed oxidation is the major fate for the BCAA and BCKA extracted during the BCAA infusion, the net uptake of BCAA and BCKA on a molar basis was equivalent to that of glucose plus lactate and could thus account for an appreciable (perhaps 10-15\%) fraction of the oxygen consumption. The use of BCAA and BCKA as oxidative fuels may also explain the diminished myocardial lactate uptake observed during BCAA infusion.

It is of interest that in the current study the large uptake of BCAA during amino acid infusion was not paralleled by an increased release of either alanine or glutamine, which are thought to be the principal amino acids involved in the export of nitrogen from muscle. These results are similar to those found during insulin and amino acid infusion in the canine heart (24) and during BCAA (15) or a balanced amino acid infusion (26) in skeletal muscle in humans. After transamination of the BCAA amino group to glutamate in the heart, the amino group may be further transaminated to alanine or released from glutamate as ammonia via either glutamate dehydrogenase or the purine nucleotide cycle $(27,28)$. We did not measure ammonia balance, but these results raise the possibility that this pathway may function in the metabolism of amino acids by the heart.

The net negative myocardial balance for phenylalanine observed in these postabsorptive subjects indicates that heart muscle is in negative protein balance after an overnight fast. Measuring the rate of phenylalanine release from a muscle bed using selective catheterization techniques is likely more sensitive at detecting net protein breakdown early during fasting than are techniques that depend on the actual loss of muscle mass (29-33). Previous studies have similarly reported a net negative balance for phenylalanine across forearm $(5,15)$ and leg (34) skeletal muscle in postabsorptive humans. Likewise, a net loss of heart mass is apparent within $48 \mathrm{~h}$ of fasting in the rat $(30,32,33)$ and proceeds at a rate of $5-7 \% / \mathrm{d}$ through $5 \mathrm{~d}$ of fasting (29-33). From the negative phenylalanine balance and the known phenylalanine content of heart protein, we estimate that the human heart is losing protein mass at a rate of $4-5 \% / d$ after an overnight fast. The loss of protein from heart and skeletal muscle occurs at a slower rate than that seen in the whole body, and in particular tissues such as liver or gut, resulting in a relative sparing of muscle protein $(32,35)$. Later in fasting, mobilization of skeletal muscle protein appears to be slowed by regulatory adaptations. A similar adaptation would need to be invoked to preserve cardiac mass during prolonged fasting though this has not been studied directly.

Presumably the net loss of phenylalanine observed postabsorptively is routinely reversed in response to eating, with changes in hormonal and substrate levels, or with hemodynamic changes during the course of the day to account for the maintenance of steady-state heart protein mass. The maintenance of heart mass must involve balanced protein synthesis and degradation when integrated over time. Whether this involves changes in protein degradation, synthesis, or both has not been studied in humans. Although heart protein degradation has been difficult to assess in vivo, heart protein synthesis is influenced by both fasting and feeding in small animals (29, 35 ) and an increase in protein synthesis after a meal may contribute to the reversal of net protein loss which occurs with fasting. The current results serve to illustrate the dynamic nature of myocardial protein metabolism in humans and that the experimental approach we introduced may afford the opportunity to define humoral, substrate, and mechanical factors which modify this process.

Acute myocardial ischemia is also associated with suppression of overall myocardial protein synthesis $(36,37)$, perhaps mediated by heat shock proteins which are expressed during ischemia (38). In the patients studied, no angina or electrocardiographic evidence of ischemia was seen over the $90 \mathrm{~min}$ preceding or during the infusion protocol, and we observed significant regional cardiac lactate extraction throughout the study. Thus, it seems unlikely that acute myocardial ischemia before or during BCAA infusion could account for our results.

The change in phenylalanine balance from a net release in the basal state to neutral during BCAA infusion strongly suggests that these amino acids have an anabolic effect on protein turnover in the human heart. Fractional rates of protein synthesis were very low before BCAA infusion but increased to $\sim 5 \% / \mathrm{d}\left(t_{1 / 2}=10.2 \mathrm{~d}\right)$. Basal protein degradation was $\sim 6 \% / \mathrm{d}$ $\left(t_{1 / 2}=8.1 \mathrm{~d}\right)$ and tended towards a slower breakdown during BCAA infusion $\left(t_{1 / 2}=10.2 \mathrm{~d}\right)$. Previous in vitro studies have shown that BCAA stimulate protein synthesis in the isolated perfused heart $(9,11)$ and decrease protein degradation in isolated atrial muscle (10), although these effects may be due in part to the additional substrate supply for fuel metabolism in the absence of free fatty acids in the in vitro perfusate. Recent experimental studies have suggested that BCAA infusion may potentiate insulin's anabolic effect on muscle protein synthesis in the rat (17). Although no animals received BCAA alone, when BCAA were infused with glucose there was a significant stimulation of protein synthesis in skeletal muscle and a trend towards increased protein synthesis in heart when compared to glucose infusion alone (17).

The mechanism by which the BCAA exert their anabolic effect on the heart is uncertain. Although amino acids may be weak insulin secretagogues, we observed no change in insulin concentration during the course of the current study. Likewise, hemodynamic factors that alter ventricular tension development have a clinically recognized long-term effect on heart mass and appear to be important determinants of myocardial protein synthesis experimentally (39). Insofar as arterial blood pressure, cardiac double product, myocardial oxygen consumption, and coronary blood flow did not increase significantly, increased myocardial work does not appear responsible for the altered protein metabolism seen with BCAA infusion.

The current results suggest that BCAA have a specific, direct anabolic action on heart protein metabolism. Others have suggested a potential clinical benefit of amino acid infusion in conjunction with cardiopulmonary bypass (40) and specifically for BCAA in myocardial ischemia (41). Whether these substances may be useful in patients with coronary artery disease 
during or after acute ischemic injury remains to be determined. Potentially, their anabolic effect on myocardial protein turnover in fasting patients may be relevant to their use as supplemental nutritional support in patients with cardiac disease and poor nutrition.

In conclusion, the dynamics of protein turnover in the human heart can be followed experimentally using the methods described and are susceptible to short-term regulation. The techniques outlined in this study may provide a useful approach for examining the regulation of cardiac protein turnover by humoral, hormonal, or hemodynamic factors in humans.

\section{Acknowledgments}

This work was supported by grants from the U. S. Public Health Service KO8 HL-01840, HL-37041, and AHA 870328, and by the Yale Clinical Research Center RR 125 and Clintec International. We express our appreciation to Jennifer Chiaia, Susan Dunn, Cheryl Farrah, Ralph Jacob, and Deborah Young for their assistance.

\section{References}

1. Carlsten, A., B. Hallgren, R. Jagenburg, A. Svanborg, and L. Werko. 1961. Myocardial metabolism for glucose, lactic acid, amino acids and fatty acids in healthy human individuals at rest and at different work loads. Scand. J. Clin. Lab. Invest. $13: 418-428$.

2. Mudge, G. H., Jr., R. M. Mills, H. Taegtmeyer, R. Gorlin, and M. Lesch. 1976. Alterations of myocardial amino acid metabolism in chronic ischemic heart disease. J. Clin. Invest. 58:1185-1192.

3. Brodan, V., J. Fabian, M. Andel, and J. Pechar. 1978. Myocardial amino acid metabolism in patients with chronic ischemic heart disease. Basic Res. Cardiol. 73:160-170.

4. Thomassen, A., J. P. Bagger, T. T. Nielsen, and P. Henningsen. 1988. Altered global myocardial substrate preference at rest and during pacing in coronary artery disease with stable angina pectoris. Am. J. Cardiol. 62:686-693.

5. Gelfand, R. A., and E. J. Barrett. 1987. Effect of physiologic hyperinsulinemia on skeletal muscle protein synthesis and breakdown in man. J. Clin. Invest. 80:1-6.

6. Barrett, E. J., J. H. Revkin, L. H. Young, B. L. Zaret, R. Jacob, and R. A. Gelfand. 1987. An isotopic method for in vivo measurement of muscle protein synthesis and degradation. Biochem. J. 245:223-228.

7. Revkin, J., L. H. Young, W. S. Stirewalt, D. M. Dahl, R. A. Gelfand, B. L. Zaret, and E. J. Barrett. 1990. The in vivo measurement of myocardial protein turnover using an indicator dilution technique. Circ. Res. 67:902-912.

8. Barrett, E. J., and R. A. Gelfand. 1989. The in vivo study of cardiac and skeletal muscle protein turnover. Diabetes Metab. Rev. 5:133-148.

9. Chua, B. H. L., D. L. Siehl, and H. E. Morgan. 1980. A role for leucine in regulation of protein turnover in working rat hearts. Am. J. Physiol. 239:E510E514.

10. Curfman, G. D., D. S. O'Hara, B. E. Hopkins, and T. W. Smith. 1980. Suppression of myocardial protein degradation in the rat during fasting. Circ. Res. 46:581-589.

11. Tischler, M. E., M. Desautels, and A. L. Goldberg. 1982. Does leucine, leucyl-tRNA, or some metabolite of leucine regulate protein synthesis and degradation in skeletal and cardiac muscle? J. Biol. Chem. 257:1613-1621.

12. Buse, M. G., H. F. Herlong, and D. A. Weigand. 1976. The effect of diabetes, insulin, and the redox potential on leucine metabolism by isolated rat hemidiaphragm. Endocrinology. 98:1166-1175.

13. Fulks, R. M., J. B. Li, and A. L. Goldberg. 1975. Effects of insulin, glucose, and amino acids on protein turnover in rat diaphragm. J. Biol. Chem. 250:290298.

14. Schwenk, W. F., and M. W. Haymond. 1987. Effects of leucine, isoleucine, or threonine infusion on leucine metabolism in humans. Am. J. Physiol. 253:E428-E434.

15. Louard, R., J. King, and R. A. Gelfand. 1988. Branched chain amino acids inhibit whole body and skeletal muscle proteolysis in man. Diabetes. 37(Suppl. 1):39a. (Abstr.)

16. Buse, M. G. 1981. In vivo effects of branched chain amino acids on muscle protein synthesis in fasted rats. Horm. Metab. Res. 13:502-505.
17. Garlick, P. J., and I. Grant. 1988. Amino acid infusion increases the sensitivity of muscle protein synthesis in vivo to insulin. Biochem. J. 254:579584.

18. McNurlan, M. A., E. B. Fern, and P. J. Garlick. 1982. Failure of leucine to stimulate protein synthesis in vivo. Biochem. J. 204:831-838.

19. Ichihara, K., J. R. Neely, D. L. Siehl, and H. E. Morgan. 1980. Utilization of leucine by working rat heart. Am. J. Physiol. 239:E430-E436.

20. May, R. C., and W. E. Mitch. 1989. The metabolism and metabolic effects of ketoacids. Diabetes Metab. Rev. 5:71-82.

21. Nissen, S. L., C. Van Huysen, and M. W. Haymond. 1982. Measurement of branched chain amino acids and branched chain alpha-ketoacids in plasma by high-pressure liquid chromatography. J. Chromatogr. 232:170-175.

22. Revkin, J., E. J. Barrett, L. H. Young, R. A. Gelfand, B. L. Zaret, and W. Stirewalt. 1988. Amino acyl-tRNA validation of the in vivo measurement of myocardial protein turnover using an amino acid tracer: ${ }^{3} \mathrm{H}$-phenylalanine. $J$. Am. Coll. Cardiol. 11:142a. (Abstr.)

23. Thompson, G. N., P. J. Pacy, H. Merritt, G. C. Ford, M. A. Read, K. N. Cheng, and D. Halliday. 1989. Rapid measurement of whole body and forearm protein turnover using a $\left[{ }^{2} \mathrm{H}_{5}\right]$ phenylalanine model. Am. J. Physiol. 256:E631E639.

24. Schwartz, R. G., E. J. Barrett, C. K. Francis, R. Jacob, and B. L. Zaret 1985. Regulation of myocardial amino acid balance in the conscious dog. J. Clin. Invest. 75:1204-1211.

25. Dahl, D. M., E. J. Barrett, and L. H. Young. 1990. In vivo anabolic effect of insulin and amino acids on the canine heart. Clin. Res. 38:271a. (Abstr.)

26. Abumrad, N. N., D. Rabin, K. L. Wise, and W. W. Lacy. 1982. The disposal of an intravenously administered amino acid load across the human forearm. Metab. Clin. Exp. 31:463-470.

27. Takala, T., J. K. Hiltunen, and I. E. Hassinen. 1980. The mechanism of ammonia production and the effect of mechanical work load on proteolysis and amino acid catabolism in isolated perfused rat heart. Biochem. J. 192:285-295.

28. Watanabe, T. 1968. Significance of ammonia in myocardial metabolism. Jpn. Circ. J. 32:1811-1814.

29. Preedy, V. R., D. M. Smith, N. F. Kearney, and P. H. Sugden. 1984. Rates of protein turnover in vivo and in vitro in ventricular muscle of hearts from fed and starved rats. Biochem. J. 222:395-400.

30. Garlick, P. J., D. Millward, W. P. T. James, and J. C. Waterlow. 1975. The effect of protein deprivation and starvation on the rate of protein synthesis in tissues of the rat. Biochim. Biophys. Acta. 414:71-84.

31. Li, J. B., and A. L. Goldberg. 1976. Effects of food deprivation on protein synthesis and degradation in rat skeletal muscles. Am. J. Physiol. 231:441-448.

32. Goodman, M. N., B. Lowell, E. Belur, and N. B. Ruderman. 1984. Sites of protein conservation and loss during starvation: influence of adiposity. Am. J. Physiol. 246:E383-E390.

33. Zahringer, J., N. Pritzl, E. Geeheeb, and G. Stab. 1985. Influence of starvation and total protein deprivation on cardiac mRNA levels. Basic Res. Cardiol. $80: 1-11$.

34. Gelfand, R. A., M. G. Glickman, R. Jacob, R. S. Sherwin, and R. A DeFronzo. 1986. Removal of infused amino acids by splanchnic and leg tissues in humans. Am. J. Physiol. 250:E407-E413.

35. Samarel, A. M., M. S. Parmacek, N. M. Magid, R. S. Decker, and M. Lesch. 1987. Protein synthesis and degradation during starvation-induced cardiac atrophy in rabbits. Circ. Res. 60:933-941.

36. Taegtmeyer, H., and M. Lesch. 1980. Altered protein and amino acid metabolism in myocardial hypoxia and ischemia. In Degradative Process in Heart and Skeletal Muscle. K. Wildenthal, editor. Elsevier/North Holland Biomedical Press, New York. 347-359.

37. Kao, R., D. E. Rannels, and H. E. Morgan. 1976. Effects of anoxia and ischemia on protein synthesis in the perfused rat heart. Circ. Res. 38(Suppl. I):I124-I130.

38. Dillmann, W. H., H. B. Mehta, A. Barrieux, B. D. Guth, W. E. Neely, and J. Ross, Jr. 1986. Ischemia of the dog heart induces the appearance of a cardiac mRNA coding for a protein with migration characteristics similar to heat-shock/ stress protein 71. Circ. Res. 59:110-114.

39. Everett, A. W., R. R. Taylor, and M. P. Sparrow. 1977. Protein synthesis during right ventricular hypertrophy after pulmonary artery stenosis in the dog. Biochem. J. 166:315-321.

40. Lazar, H. L., G. D. Buckberg, A. M. Manganaro, and H. Becker. 1980. Myocardial energy replenishment and reversal of ischemic damage by substrate enhancement of secondary blood cardioplegia with amino acids during reperfusion. J. Thorac. Cardiovasc. Surg. 80:350-359.

41. Uretzky, G., I. Vinograd, H. Freund, E. Yaroslavsky, Y. J. Appelbaum, and J. B. Borman. 1984. The protective effect of the branched chain amino acids in myocardial ischemia. J. Am. Coll. Cardiol. 3:608a. (Abstr.) 